\title{
Armero: crónica de un desastre anunciado u oda a la negligencia humana
}

\author{
Armero: Chronicle of an Announced Disaster \\ or Ode to the Human Negligence
}

Javier Enrique Thomas Bohórquez ${ }^{1}$

Departamento de Geografía Universidad del Valle

El trece de noviembre marcó una fecha en la cual fueron varias las tragedias que se presentaron: haberlo perdido todo de la noche a la mañana $y$ tener que soportar tantas humillaciones. Carmenza: Una sobreviviente.

\section{Resumen}

Hablar de lo ocurrido en Armero, el fatídico 13 de noviembre de 1985, no sólo trae a la memoria los confusos, absurdos y dolorosos hechos que aún enlutan el corazón de muchas familias colombianas, sino que por la magnitud alcanzada es referirse a un hito mundial en la historia de los desastres. Este escrito pretende dejar algunas reflexiones sobre este acontecimiento y más allá de él, algunos forzosos pero necesarios aprendizajes en un contexto, mundial y nacional, en el que nunca habrá suficiente, o en demasía, "cultura de la prevención". El trabajo consta fundamentalmente de dos partes; la primera identifica y caracteriza la amenaza y los mecanismos involucrados en ella y en la segunda se retoman elementos tanto del "modelo PAR" (presión y liberación de desastres), como del llamado "modelo de acceso", para hacer un análisis que procura reconstruir las condiciones políticas, sociales, institucionales, económicas y culturales que definieron una alta vulnerabilidad y que se combinaron

${ }^{1}$ Ms. C en Geografía, Ms.C en Desarrollo Sustentable. Profesor Asociado del Departamento de Geografía de la Universidad del Valle.jenthobo@univalle.edu.co 
para configurar el desastre ocurrido. Pretende también, hacer un homenaje a todos aquellos 20.000 o más seres anónimos desaparecidos en una noche, cuyos nombres sólo conocen los familiares que les sobrevivieron y que desafortunadamente el país no sólo desconoció, sino que olvidó.

Palabras Clave: Armero, amenaza, desastre, vulnerabilidad, modelo PAR.

\begin{abstract}
To speak of the happened thing in Armero, tragic 13 of November of 1985, not only brings to the memory the confused, absurd and painful facts that be in mourning still the heart of many Colombian families, but that by the reached magnitude is to talk about to a world-wide landmark in the history of the disasters. This writing tries to leave some reflections on this event and beyond him, some unavoidable but necessary learning's in a context, world-wide and national, in which never it will have sufficient, or too much, "culture of the prevention". The work consists fundamentally of two parts; first it identifies and it characterizes the threat and the mechanisms involved in her and in second as much retake elements of the "PAR model" (pressure and liberation of disasters), like of the call "access model", to make an analysis that it tries to reconstruct the political conditions social, institutional, economic and cultural, that defined a high vulnerability and that was combined to form the happened disaster. It also tries, to make a tribute to all those 20,000 or more disappeared anonymous beings in one night, whose names only know the relatives who survived to them and who unfortunately the country not only did not know, but that it forgot.
\end{abstract}

Key Words: Armero, Hazard, disaster, vulnerability, PAR model.

\title{
1. La amenaza
}

Existen distintos acercamientos al concepto de amenaza natural (ONAE 1987; Cardona 1990; Hermelin 1993; O.E.A 1993; Wilches 1993; Coch 1995; Kovach 1995; PNUD UNDRO- DAH 1991; Wisner 
2004; entre muchos otros); sin embargo, a pesar de algunas diferencias, todas coinciden en identificar en ella dos elementos estructurales; de una parte un fenómeno o evento potencialmente destructor y de otra una población que puede resultar afectada ante la ocurrencia de éste.

En este escrito se entiende ésta, como "la posibilidad de ocurrencia de un evento natural (movimientos en masa, terremotos, inundaciones, vulcanismo, etc.), que genere peligro para el hombre y/o sus actividades, expresada por la combinación de diversas variables en intensidades diferentes y en donde una de ellas actúa como factor desencadenante (mecanismo disparador), con una magnitud determinada, presente en cierto lapso de tiempo y en un lugar específico" (Thomas, J. 2000: 370).

En el caso concreto de Armero, convergieron un número importante de condiciones y variables diversas que no obstante estar concatenadas estructural y funcionalmente, responden a mecanismos distintos y que es necesario separar analíticamente para comprender su participación y responsabilidad en el evento y en el cuadro final que se configuró.

\subsection{El punto de partida: condiciones físico-naturales}

Los Andes colombianos, en sentido estructural, están formados por cuatro cordilleras (Acosta, 1982; Toussaint, 1978): Oriental, Central, Occidental y de la Costa (conocida como la Serranía del Baudó). Estas cordilleras, a modo de bloques levantados, están separadas por cuencas de sedimentación (depresiones tectónicas) que recogen los ríos más importantes del país y donde, por condiciones edáficas y bióticas resultantes, se localiza un porcentaje importante de la población colombiana.

Barrero et ál. (1969) consideran que la Cordillera Central es el umbral de convergencia entre los dominios oceánicos al occidente y continentales al oriente. La estructura y su relieve son el resultado de varios eventos tecto-orogénicos, magmáticos y metamórficos, relacionados con la acreción de la corteza oceánica al continente (París y Marín, 1979) y explicados en función de la tectónica de placas (Barrero, 1977; Restrepo \& Toussaint, 1976). Esta tuvo su mayor levantamiento en el Plioceno 
(Van der Hammen, 1958) y fue levantada en bloques separados por fallas inversas (Irving, 1971), lo cual generó relieves en contrapendientes (abruptos y con enorme potencial morfogénico); levantamiento que, según Luschen (1983), continúa dándose a una tasa de cinco a diez mm/ año, acentuándose así la disección fluvial, la generación de pendientes mayores y el carácter torrencial de las corrientes.

Igualmente, debido al esfuerzo tectónico compresivo, asociado a la formación del relieve, y la misma dinámica tectónica actual (convergencia-subducción) el territorio colombiano, presenta un sistema de fallas en sentido SE-NW (Romeral, Cauca-Patía, La Palestina, y la del borde este de la Cordillera Oriental, entre las más significativas). También se originan fallas de rumbo, como la de Bucaramanga-Santa Marta que desplazó la Sierra Nevada de Santa Marta; un ente tectónico de la Cordillera Central, hacia el noroeste por varios kilómetros.

Justamente, debido a la presencia de estas fallas en los contactos entre las oroestructuras (cordilleras de plegamiento) y las cuencas de sedimentación (valles aluviales), grandes y numerosas corrientes de agua están controladas tectónicamente y diversos tramos rectilíneos aumentan la velocidad y competencia de estas para transportar sedimentos, aumentando su capacidad torrencial.

La acumulación de materiales transportados por dinámica volcanoglaciar, fluvio-volcánica, fluvio-glaciar..., se ha hecho fundamentalmente en los piedemontes a lado y lado de la cordillera en el contacto escarpes tectónicos-fosas tectónicas y en forma de conos de deyección o conosterraza. Los materiales dominantes son volcano-detríticos: La mayoría de los conos de los piedemontes sobre las fosas del Magdalena y del CaucaPatía tienen una cobertura de origen fluvio-glaciar y fluvio-volcánico correspondientes con la última glaciación, pero debajo se encuentran otras capas más antiguas y en superficie ocasionalmente hay capas de edad holocénica, algunas registradas en el período histórico (Flórez, A \& La-Rotta E. 1986d: 165).

Adicionalmente a las condiciones tectónicas, geológicas y volcánicas descritas, la geomorfología y climatología colombiana potencian aún más 
la ocurrencia de fenómenos gravitacionales extremos por cuanto encauzan y/o aumentan el potencial hidrogravitatorio existente. Precisamente, el modelado de disección, resultante de procesos erosivos concomitantes a su vez al levantamiento de la cordillera, favorece la formación de cañones que aumentan la velocidad y competencia de los ríos. Las figuras 1 muestra el cañón del río Lagunillas por donde la avalancha de lodos y escombros arrasó la población de Armero.

En eventos extremos, como los fluvioglaciares o fluviovolcánicos o en épocas de altas precipitaciones cuando hay aumento de escorrentía, avalanchas o avenidas torrenciales, respectivamente, son potencialmente formables y su salida abrupta a las cuencas sedimentarias (Magdalena y Cauca principalmente) es la responsable de la formación de abanicos y conos que se solapan entre sí y definen, contradictoriamente, suelos muy fértiles pero en condiciones de exposición muy alta para las poblaciones que buscan su explotación. La formación de cañones en la ladera y de conos torrenciales (compuestos por materiales volcánicos) en los piedemontes y parte del valle, por los ríos Lagunillas y Gualí, ver figura 2 , configuran el marco geomorfológico que potencia eventos torrenciales y por ende las amenazas.

De otra parte, los Andes Colombianos alcanzan sus mayores altitudes en la cordillera central, allí en varios sectores se superan los $4.800 \mathrm{~m}$ de altitud, límite inferior promedio de los glaciares actuales (nevados). En el país es posible hablar de 10 nevados, de los cuales 8 se hallan sobre estructuras volcánicas de la cordillera central. En estricto sentido, de estos 8 solamente la mitad (Ruiz, Santa Isabel, Tolima y Huila) pueden ser considerados verdaderos glaciares (nevados) ya que los demás solo se cubren con delgadas capas de nieves temporales. A pesar de que su extensión y volumen no han sido recientemente medidos en campo, Flórez (1986d) con base en el método fotogramétrico indirecto, propuesto por Lagarec \& Cailleux² (1972), los calculó (ver tabla No. 1).

\footnotetext{
${ }^{2}$ El método relaciona el espesor máximo con la superficie de los glaciares de montaña por medio de la ecuación $\mathrm{Y}=0.41 \mathrm{X}-1.13$ en la que $\mathrm{Y}=$ logaritmo decimal del espesor máximo en metros y $X=$ logaritmo decimal de la superficie en $\mathrm{km}$. Luego, mediante la correlación $\mathrm{R}$ entre el espesor medio y el espesor máximo con una mediana de 0.40 , se calcula el espesor medio y de ahí, conociendo la superficie, se calculó el volumen.
} 
Las cifras referidas muestran claramente como existe un potencial hidrogravitatorio importante en los volcanes nevados del país que en eventuales fusiones y/o descongelamientos generarían eventos extremos en la unidades funcionales inferiores (morfogénicas y topográficas), evidenciado el comportamiento en catena (Scheidegger, A. 1988) y los mecanismos modeladores del sistema de transferencia (Scheidegger, A. 1987).

En síntesis, es evidente que la presencia de glaciares se suma a la tectónica y el volcanismo activo para hacer de la cordillera central y de sus áreas de influencia una región de inestabilidad real y potencial de carácter catastrófico.

\subsection{El nevado del Ruiz. Características}

El volcán del Ruiz (llamado también Cumanday) está ubicado, a $4^{\circ} 53^{\prime} 42^{\prime \prime}$ de latitud norte, $75^{\circ} 19^{\prime} 24^{\prime}$ " de longitud oeste a una altitud de 5.230 m.s.n.m.; el diámetro del cráter es de 760 mts. Sobre el volcán se asienta una masa glaciar de 1.900 has con un volumen aproximado de 294x10" m³ (Flórez, A. \& La-Rotta, E. 1986d), hace parte como ya se expresó, del macizo volcánico Ruiz-Tolima.

Según Robertson et ál. (2002) éste ha sido erróneamente clasificado por algunos, como volcán tipo escudo por su gran extensión y pendientes moderadas.

Su edificio volcánico está construido por múltiples flujos de lavas andesíticas, dacíticas y piroclastos a partir de numerosos focos desde hace 1 millón de años. Esta fase fue seguida por un periodo explosivo, sucediendo luego una reconstrucción desde hace 0.5 Ma. (Herd, 1982). Es de destacar la presencia de dos estructuras adventicias importantes, La Pirámide o Piraña al Este y La Olleta situada al Oeste. La histórica reciente del volcán señala frecuentes flujos piroclásticos y lahares que han afectado los valles circundantes (Robertson et ál. 2002: 57-58)

A partir tanto de registros geológicos como históricos ha sido posible establecer que el volcán a lo largo de su historia ha pasado por diferentes tipos de actividad, siendo dominantemente explosiva en el período 
histórico con proyecciones de materiales piroclásticos (cenizas, arenas, lapilli, pómez), gases y vapor de agua. Thouret et ál., (1985) establecieron que las principales reactivaciones durante el Holoceno sucedieron hace $10.400,6.200,5.200,3.100,2.600,2.000,1.200,1.000,800$ y 600 años. Se conocen también relatos históricos sobre reactivaciones que produjeron avalanchas hacia el valle del río Magdalena especialmente a lo largo de los ríos Azufrado-Lagunillas sobre el cono de Armero. Es así como Borrero, P. \& Cruz G. establecen un registro de la actividad histórica del Ruiz (ver Tabla No. 2), relacionando a su vez el índice de explosividad volcánica (VEI) ${ }^{3}$.

Ellos mismos identifican, con base en Guarnizo et ál. (1996), una última avalancha en el río Lagunillas el 15 de enero de 1995, con una duración de 4 horas y 15 minutos; Sin embargo, como este fenómeno se debió a un deshielo del glaciar que alimenta el río Lagunillas sin estar precedida por actividad sísmica o eruptiva (Borrero, C. \& Cruz, G. 1: 3 ) no se tuvo en cuenta para el registro histórico relacionado anteriormente.

A partir de los datos suministrados es posible concluir que en tiempos históricos, con ciertos intervalos de inactividad el carácter explosivo del volcán, con expulsión de piroclastos, se ha mantenido (cenizas, lapilli, bombas freáticas, pómez); igualmente, como la actividad fumarólica ha sido más o menos constante.

\subsection{Se despierta el monstruo: antecedentes y premonitores}

El Instituto Geológico y Minero de Colombia (INGEOMINAS) en su portal corporativo hace un recuento del proceso de reactivación del volcán desde finales de 1984 y las acciones institucional es implementadas para afrontar este hecho.

La reactivación empezó a hacerse evidente a finales de 1984; debido a la actividad eruptiva (rugidos con emanaciones de gases sulfurosos y vapor de agua), notorios cambios en la tonalidad del glaciar y repetidos sismos de baja intensidad, empezaron a hacerse visibles.

${ }^{3}$ Este índice fue desarrollado por Newhall and Shelf (1982, en Fisher and Smincke, 1984); es una escala de comparación de los diferentes episodios eruptivos entre los diferentes volcanes del mundo; comienza en 0 y va hasta 8 ). 
El 22 de diciembre hubo una serie de temblores, uno de ellos con magnitud de 4 en la escala de Richter, acompañado de pequeñas explosiones que arrojaron lodos sulfurosos y cenizas. El primer temblor a las cinco y media de la tarde fue seguido por un tremor armónico percibido durante media hora.

Justamente, debido a este incremento de la actividad sísmica y fumarólica del volcán, se creó, a comienzos de 1985, el "Comité de Estudios Vulcanológicos de la Comunidad Caldense", con la participación de universidades, Instituciones estatales y gremiales y comunidad en general. En agosto de ese año INGEOMINAS, con la participación activa del mencionado comité, las universidades de la ciudad, las instituciones especializadas y las autoridades departamentales y municipales, presentó a las autoridades civiles y militares y a los medios de comunicación, el mapa preliminar de amenaza volcánica, considerado en ese momento como: "Mapa Preliminar de Riesgos Volcánicos Potenciales del nevado del Ruiz (ver Fig. No. 3).

El 6 de septiembre comenzaron cinco días de sismos pre-erupción; los sismógrafos registraron un patrón muy regular, consistente en períodos de 15 minutos de fuertes temblores de alta frecuencia, a intervalos de una hora.

Según los reportes oficiales, el 11 de septiembre una fuerte actividad freática se inicia. La emisión de cenizas desde el cráter Arenas comenzó a la una y media de la tarde y duró siete horas, acompañada por un rugido y por descargas eléctricas; hubo caída de cenizas a $30 \mathrm{kms}$. del volcán y cayeron bombas de piroclastos en campos de nieve a $2 \mathrm{kms}$. del cráter. La red de sismógrafos registró tremores en intervalos de 1.5 horas antes de la erupción y continuamente durante la caída de cenizas. Un lahar de tamaño moderado empezó a las 18:30 horas en el flanco NE del volcán, avanzando $17 \mathrm{kms}$. por el valle del río Azufrado desde $4.700 \mathrm{~m}$ a 3.000 $\mathrm{m}$ de altura, con velocidad estimada de 10 a $30 \mathrm{kms}$. por hora $(\mathrm{KPH})$, bloqueando una carretera del lado oriental.

La más fuerte liberación de energía sísmica en el Ruiz ocurrió en los días anteriores a la emisión de ceniza del 11 de septiembre, según los sismógrafos, la tasa de energía liberada se incrementó antes de la 
erupción del 13 de noviembre, pero más gradual que en la actividad anterior al 11 de septiembre.

El INGEOMINAS relata así los hechos:

Una emisión de ceniza de carácter freático en el volcán asociada a una fuerte actividad sísmica, ocurrida el 11 de septiembre de 1985, se convirtió en el factor que volcó la atención a la reactivación del volcán nevado del Ruiz por parte de las entidades del orden departamental y nacional. El 13 de septiembre, el Comité de Estudios Vulcanológicos de la Comunidad Caldense en Manizales emitió una alerta por la grave amenaza de avalanchas adicionales de roca y hielo y se unió con la Defensa Civil y la Gobernación del Departamento de Caldas para recomendar la evacuación a lo largo de los ríos alimentados por la nieve y el hielo del volcán nevado del Ruiz. Estas advertencias recibieron considerable atención por parte de los medios masivos de comunicación.

Estos eventos generaron una avalancha de hielo y lodo circunscrita a las cabeceras del río Azufrado.

El 10 de noviembre se registró el comienzo de un tremor continuo de tres días, a 78 decibeles, muy legible pero con menor cantidad que durante la erupción del 11 de septiembre. No hay acuerdo sobre la hora de iniciación de la erupción del miércoles 13 de noviembre, por cuanto los sismógrafos estaban saturados; sin embargo, se cree que ocurrió entre las 15 y 16 horas, puesto que los registros no mostraron actividad sísmica especial antes de las 15:45 horas.

\subsection{El 13 de noviembre: se dispara el sistema de amenazas}

Habíamos expresado con anterioridad que la amenaza surge de la combinación de diversos factores que al conjugarse determinan, en un lugar y momento precisos, la ocurrencia de un evento potencialmente destructor, para el hombre, sus propiedades y/o sus actividades, como producto de ciclos naturales que describen en términos estadísticos "cierto comportamiento previsible". Pero la amenaza no se comporta como un hecho único, entendido como un momento espacio-temporal rígido y aislado, sino como la síntesis de situaciones físico-naturales y socio-culturales 
diferentes y dinámicas que se van "acumulando" e interactuando. Es decir, la amenaza actúa como un sistema, porque requiere la compleja e iterativa conjugación de factores, para que al final se rebase determinado "umbral de seguridad" (paso del comportamiento del fenómeno como evento a éste como amenaza). En esta red de factores físico-naturales que componen el medio, uno u otro, o varios a la vez, pueden resultar desestabilizados por la presencia de un evento primario o disparador (amenaza primaria o inicial), que establezca efectos colaterales a este (co-amenazas), o incluso llegar a ocurrir otros eventos posteriores de diferente origen, tipo y magnitud (amenazas secundarias o secuenciales), generándose así intrincados sistemas de amenazas.

El sistema de amenazas, es la respuesta múltiple y compleja del medio natural, frente a la sinergia establecida entre los procesos de evolución natural (funcionamiento, junto con sus alteraciones funcionales) y aquellos antrópicos de valoración, ocupación y explotación del mismo.... Es claro entonces, que el sistema de amenazas, en sentido estricto, casi siempre se comporta de forma diferente, lo que se puede establecer son algunos patrones generales de comportamiento (modelos), que ayuden a prever y "predecir" los probables efectos causados y orientar el diseño y construcción de medidas de contingencia. Así lo entienden Dollfus \& Ercole (1996:9), cuando afirman que las amenazas "son un tipo de sistema no lineal: las mismas causas no producen los mismos efectos y pequeñas causas grandes consecuencias.

Es así como un sistema de amenazas se puede entender como la posibilidad de ocurrencia de una red de eventos naturales potencialmente destructores para el hombre, que se expresan de forma simultánea o en cadena, como resultado de los nexos estructurales y funcionales de las dinámicas naturales del medio, con una(s) magnitud(es) determinada(s), presentes en cierto lapso de tiempo y en un lugar específico. Precisamente, el 13 de noviembre de 1985 esto fue lo que realmente ocurrió, debido a la compleja combinación de factores vulcanoglaciares en el marco de una geomorfología particular, se configuró un "sistema de amenazas vulcanismo-avalanchas-deslizamientos-inundaciones" (Thomas, J. 2000) que arrasó la ciudad de Armero. 
Ese día, hacia las cuatro de la tarde, la actividad volcánica entró en una fase crítica y se produjo la primera de una serie de explosiones con emisión de cenizas, gases sulfurosos y arenas; Tefra al Norte y Noreste y bombas de piroclastos fueron dispersados en un área de aproximadamente $50 \mathrm{Kms}$ a la redonda.

En la población de Herveo (a $26 \mathrm{Kms}$. al noreste) se depositó una capa de ceniza de $1 \mathrm{~mm}$ de espesor en los techos de las casas. Esta, que cayó como lluvia ácida, causó la oxidación de los techos metálicos en las edificaciones del área, en cuestión de horas.

La fase paroxismica de la erupción comenzó alrededor de las 21:10. Dos fuertes explosiones (dirigidas hacia el noreste) coincidieron con el comienzo de un tremor armónico a gran escala, el cual empezó a las 21:05 y duró casi una hora. Cerca de las 21:30 hubo una formación de una columna eruptiva, su precipitación incluyó algo de líticos, escoria y fragmentos de pómez joven incandescentes. Dicha colada derritió con rapidez grandes volúmenes de nieve superficial y hielo, también causó la rotura súbita de glaciares (González, J. sin fecha: 6).

Como lo expresa González, debido a estas explosiones empezaron a desprenderse bloques de hielo produciendo una avalancha de tipo lahar que incluyó materiales piroclásticos y detritos de las laderas. La avalancha se encauzó principalmente por el río Azufrado-Lagunillas y secundariamente por el río Gualí, afluentes del Magdalena, por cuanto el cráter que hizo erupción está localizado hacia allí. La presión de la explosión, aunque considerada geológicamente como leve (ver tabla No. 2) fue suficiente para causar el despegue de una masa de hielo al noroeste del cráter sobre la cuenca del río Molinos-Chinchiná.

Como consecuencia de lo bajo de la energía liberada, una gran porción de los productos eruptivos jóvenes y con alta temperatura, cayó sobre el casquete de hielo. La calda de tefra duró por lo menos 75 minutos e inició la fusión superficial de nieve y hielo, indujo el flujo rápido de agua y nieve en fusión. La mezcla resultante, de agua y piroclastos, fue conducida hacia la Quebrada Nereidas y el río Molinos al NW. los ríos Gualí y Azufrado al NE, y el Lagunilla al E. Estos flujos, erodaron 
profundo en depósitos no consolidados y en el manto de roca meteorizada bajo el hielo y se transformaron en flujos de lodo o lahares a unos pocos kilómetros de su fuente. Los flujos en el Azufrado y el Lagunilla fueron aumentados por la falla masiva de glaciares, ya agrietados desde antes de la caída de tefra. (ver Fig. No. 4).

Los lahares empezaron aproximadamente a las 21:20 hrs. Puede pensarse que en el Azufrado hubo dos lahares, el primero del tipo de inundación por creciente debida al lavado laminar de nieve en fusión; el segundo fue de tipo torrencial, desgarre, que paso a flujo de detritos y luego a un modo fluvial.

Se informó de caída de cenizas con mayor intensidad hacia el Este del Ruiz. A cinco km del cráter se encontraron tetras de la explosión principal que llegaron a $7 \mathrm{~cm}$ de espesor, e incluyeron fragmentos ocasionales de pumita de $30 \mathrm{~cm}$. El espesor disminuyó con la distancia y sólo fue de 1 a $2 \mathrm{~mm}$ de espesor en Armero (46 km al ENE del cráter), Mariquita (59 $\mathrm{Km}$ al NE). Hubo reportes de ceniza en poblaciones al Norte de Bogotá, en Tunja (225 Km al ENE). Bucaramanga (345 Km a) NE) y Táchira, Venezuela (a $500 \mathrm{~km}$ al NE).

En opinión de Calvache, Carrecedo y otros, va/e la pena destacar que una erupción relativamente pequeña, con emisión de material piroclástico de $10^{7}$ a $10^{8}$ metros cúbicos (estimativo provisional) produjo flujos de lodo catastróficos. Esto puede explicarse por la rápida erosión y fusión del casquete de hielo en volumen estimado de 20 a 32 millones de metros cúbicos (valor que representa del $8 \%$ al $10 \%$ del volumen total probable de hielo y nieve), debidas a la eficiencia del proceso de transferencia de calor durante la interacción piroclastos-hielo, en el desarrollo temporal de los eventos eruptivos. El colapso de bloques de hielo, en las márgenes inestables del glaciar Azufrado-Lagunilla, fue otro hecho importante (González, J. sin fecha: 6-7).

Según Flórez, A\& La-Rotta, E. (1986d), antes de la explosión el área del glaciar era de $19 \mathrm{kms}^{2}$ y con la explosión se desprendieron casi $2 \mathrm{kms}^{2}$ del casquete del glaciar (ver tabla No.1) y una superficie aproximada de $4 \mathrm{Kms}^{2}$ sufrió deshielos superficiales parciales. La velocidad de las avalanchas, en la boca del cañón (justamente donde estaba localizada la población de Armero), fue calculada por García \& Rodríguez (1986, citado en González) por encima de los $40 \mathrm{~km} / \mathrm{h}$ ora; estas tuvieron efectos 
de barrido sobre el fondo y bermas de los cauces, destrucción de la vegetación y obras de infraestructura. La acción devastadora fue mayor en los puntos de inflexión o salida de los ríos de la cordillera hacia el piedemonte, el desborde producido sobre el cono de Armero cubrió 2.590 ha de las 5.780 del total del cono Sobre el río Chinchiná (en la cuenca del río Cauca) los efectos estuvieron limitados a los bordes mismos del cauce, área en la que perecieron más de 2.000 personas.

De acuerdo a los relatos de los sobrevivientes y a las evidencias mismas en campo, en Armero la altura máxima del flujo de lodo fue de 4 a $5 \mathrm{~m}$ (ver figura 5).

De conformidad con estos mismos relatos, al parecer hubo varias oleadas de la avalanchas; la inicial, de carácter más fluido (menos viscosa), de baja temperatura, fue seguida de otra que fue considerada por sobrevivientes como "la verdadera bombada" (Cruz, C. et ál. 1995), con ruido atronador, que similar a la cuchilla de un inmenso "bulldozer" venia aplastando y tragándose todo.

La misma avalancha principal tuvo diferentes grados de densidad, velocidad y viscosidad, González (sin fecha) considera que el ramal principal (de $\mathrm{W}$ a $\mathrm{E}$ ) fue más líquido y violento que los demás; una lengüeta desprendida del ramal NE, que irrumpió en la parte de la ciudad donde quedaron edificaciones semidestruidas o parcialmente cubiertas de lodo (en cuyo borde sur quedó el edificio del hospital -ver fig.6 -), era de alta viscosidad, espeso y con abundancia de bloques de $30 \mathrm{~cm}$ de diámetro o más. Esta masa tuvo menor velocidad y se movía en impulsos; dio tiempo para que se salvaran muchos habitantes del sector que desplazaron hacia la colina que remata más al oriente en el lugar del cementerio local, que no sufrió daño alguno.

El mosaico de la figura 7 evidencia el tamaño de la tragedia. La primera aerofotografía muestra la localización de Armero en la garganta del cañón del río Lagunillas, aprovechando precisamente la fertilidad de los suelos propios de dinámicas aluviales y fluviovolcánicas, el tamaño de la ciudad (que sugiere a su vez la importancia que ésta tenía en el contexto regional) y la extensión y significancia de las actividades agrícolas desarrolladas en el valle aluvial. La segunda fotografía aérea, tomada diez días después 
del desastre, expone la devastación de la ciudad, la violenta avalancha arrasó con prácticamente toda la población. Solamente la parte más alta, al NE, alcanza a notarse por encima del lodo; sin embargo, el impacto fue tan significativo que las edificaciones que quedaron en pie fueron cubiertas por lodo hirviente hasta una altura de $1.8 \mathrm{mts}$.

\section{Pérdidas e impactos}

Los autores más conservadores hablan de 18.000 víctimas las dejadas por la avalancha y otros hablan hasta de 25.000 y 30.000 entre muertos y desaparecidos. Sin saber con precisión el número verdadero de víctimas (en el momento, por el caos reinante y la falta de experiencia en el manejo de este tipo de situaciones, no se levantó ni sistematizó información que permitiera establecer este dato con fiabilidad) lo indudable es que, sean 20 ó 30 mil, es la mayor tragedia que ha sufrido el país y una de las más grandes en el mundo asociadas a eventos volcánicos.

No obstante, resulta claro que los impactos humanos (en términos, psicológicos, sociales y culturales) rebasan significativamente el ejercicio de calcular el número de muertos, heridos o afectados directamente por la avalancha. La ruptura de los tejidos familiares y sociales generados por el evento en sí o en el momento de rescate, atención y/o relocalización son difícilmente calculables y más aún, resarcibles.

Por las circunstancias, miembros de familias sobrevivientes fueron dispersados forzosa y silenciosamente en la mayoría de los casos sin conocimiento ni mucho menos consentimiento propio. Una diáspora de Armeritas se produjo, no sólo en Guayabal (usado desde esos mismos días como escenario de "reasentamiento"), Honda, Mariquita e Ibagué, sino en la misma Bogotá; sobrevivientes que o bien sufrían trato de "arrimados" y por ende tenían que soportar vejámenes y humillaciones; bien como ejemplares "raros" susceptibles de ser "mostrados" o utilizados para obtener "beneficios económicos" por parte de terceros "supuestamente" interesados en su situación; o bien eran tratados como seres "dignos de lástima", pobrecitos y abandonados de Dios.

Ahora, en cuanto al manejo de los dineros y otras donaciones que hizo el fondo de Reconstrucción Resurgir fue pésimo, porque allí era 
donde llegaban canalizados todos los auxilios, tanto nacionales como internacionales. Por ejemplo, de la Argentina mandaron toneladas de enlatados, carnes en muy buen estado; de los Estados Unidos mandaron cantidad de leche y comida en buen estado; pero llegaban a Barranquilla y se quedaron botados porque el Fondo jamás fue a reclamar eso, ni hizo llegar a los damnificados la ropa que llegaba de buena calidad, dicen que se la repartían entre personas que no tenían que ver con la tragedia (Cruz, C. et ál. 1995:116).

Ninguno de estos tratos anteriores dignificó su condición de seres humanos y propició su proceso de recuperación psicológica y física ${ }^{4}$, ni tampoco facilitó las condiciones necesarias para restablecer los lazos familiares, sociales y culturales rotos o su reinserción a procesos productivos. En el mismo sentido, tampoco hubo programas sistemáticos de generación de condiciones favorables a la reorientación y/o reacondicionamiento laboral de los sobrevivientes, ni mucho menos proyectos productivos que les permitieran reconfigurar sus proyectos de vida y olvidar su historia y condición de víctimas y más que ver con esperanza, construir su futuro.

Del lado de los impactos económicos, estos fueron avaluados en ese momento por el Departamento Nacional de Planeación, por el orden de 212 millones de dólares (ver tabla no. 3).

Igual que con la evaluación de víctimas, en los datos referenciados se aprecia que en el cálculo de pérdidas sufridas por el desastre de Armero, solamente se incluyen aquellos producidos directamente por el evento catastrófico ya descrito; sin embargo, es indudable que los costos inherentes a resarcir, readecuar, recuperar, relocalizar o reacondicionar a las víctimas o a rescatar o resignificar su historia y sociedad rebasan con creces los guarismos presentados.

\footnotetext{
${ }^{4}$ ¿Qué hacer con la impronta indeleble que circunstancias como estas deja en cuerpo y mente de niños, jóvenes, adultos y ancianos? ¿Cómo, con quién y para qué enfrentar y/o superar los traumas sufridos y retomar proyectos de futuro? Sin discusión alguna el Estado, como responsable, directo o indirecto, de la configuración de situaciones como ésta y acorde con su esencia y alcances éticos, políticos, jurídicos y administrativos adquiere compromisos ineludibles en el acompañamiento y "solución" de estas demandas y requerimientos conexos.
} 


\section{Armero: la cadena de vulnerabilidades}

El modelo presión y liberación de los desastres (PAR), parte del supuesto que los desastres se originan por la intersección de dos fuerzas opuestas: la exposición física a una amenaza de un lado, y de otra parte aquellos procesos que generan vulnerabilidad de las comunidades ante esa amenaza en particular (Wisner, Ben et ál. 2004). A su vez, en relación con las condiciones que producen una progresión de la vulnerabilidad, identifica tres: las causas de fondo, las presiones dinámicas y ciertas condiciones inseguras; al final, el desastre surge a partir de la "incapacidad" de la sociedad de liberar presión en aquellos factores que hacen vulnerable a la población.

Antes de revisar, con base en el modelo PAR, los elementos que generaron la progresión de la vulnerabilidad en Armero, es necesario acercarse al concepto mismo de vulnerabilidad; ésta se puede entender como el

nivel de exposición y resistencia que se ofrece a la presencia de amenazas (esto involucra acciones para evitar, como para resistir el impacto), que está dada por los condicionamientos socio-culturales o adaptabilidad de los grupos humanos (tecnología), incluyendo la percepción de la amenaza misma y la conscientización que se tiene acerca de la posibilidad de ser afectado por un evento catastrófico (riesgo). Adaptación que, en el caso específico de las amenazas, involucra medidas para controlar (regular la frecuencia y/o atenuar la intensidad del evento), resistir (soportar la manifestación y sus consecuencias) y/o aprovechar el evento (algún tipo de utilización de la manifestación); esto engloba obligatoriamente ciencia y tecnología, niveles de percepción, procesos históricos de ocupación y explotación y por supuesto recursos financieros; es decir, cultura, en su sentido más amplio (Thomas, 2005: 94).

Quiere esto decir, que la vulnerabilidad de la población ante un fenómeno determinado, no se puede concebir como una actitud pasiva, en la que sólo se sufre las consecuencias de un evento natural; sino que involucra mecanismos, tanto sistemáticos como aleatorios de adaptación y re-adaptación, en miras a generar cierta estabilización funcional (ajuste 
u homeóstasis), por medio de un aminoramiento de las alteraciones y/o rupturas de las actividades humanas.

Genéricamente, en cuanto a la naturaleza progresiva de la vulnerabilidad, es posible afirmar que ella está asociada, por una parte a la entropía misma de la infraestructura física (Romero \& Maskrey, 1993) y segundo, a los diversos condicionamientos sociales, políticos y culturales que subestiman, por conveniencia o familiaridad, los factores amenazantes -entropía social-.

En el caso de Armero es indiscutible que se fueron tejiendo, a lo largo del tiempo, progresiva y firmemente una serie de vulnerabilidades que configuraron las condiciones propicias para que el desastre fuera de la magnitud alcanzada (ver figura No. 8).

\subsection{Causas de fondo}

Por causas de fondo se entienden aquellos elementos estructurales en la sociedad y que están asociados a la forma como se organiza y distribuye el poder en ella (político, económico) y los matices espaciales o étnicos que adopta.

El excesivo centralismo del Estado Nacional existente en ese momento; el acceso inequitativo al poder político y en menor medida al económico; el desprestigio y descreimiento en la clase política dirigente, local y regional; un fuerte arraigo de una visión teológica en la población y de acatamiento del clero; $y$, una inexistencia absoluta de una cultura de la prevención; se pueden relacionar como las causas de fondo presentes en Armero, que definieron la estructuralidad de la vulnerabilidad de la población.

Antes de la promulgación de la Constitución política de 1991 la estructura político-administrativa del Estado Colombiano estaba centrada en la Nación; ésta representaba la unidad que definía el territorio y el eje central en la formulación de políticas; era para ella, en función de ella y a través de ella (con sus visiones, lógicas y ritmos) que no sólo se tomaban las decisiones sino que también se identificaban problemas, se establecían jerarquías y se definían métodos y procedimientos de resolución de éstos. 
Una excesiva concentración no sólo de poder, sino de población, bienes y servicios, se estableció en la capital nacional (Bogotá), en buen entender y apariencia, connatural localización física y espacial de los aparatos administrativos del Estado Nacional. Cualquier decisión distinta a "administrar" localmente el estado, rebasaba el ámbito puntual de respuesta (con mayor razón aquellas estructurales a la Nación y su territorio) y municipios y departamentos dependían entonces de su capacidad de gestión política (lobby) ante el ente central. Sin duda alguna esto definía un retraso importante entre la dinámica evolutiva territorial (estructuras regionales y cambios físico naturales) y la capacidad de respuesta y ajuste del Estado ante las nuevas demandas y exigencias sociales.

En las premoniciones del evento, cuando éste ya se presagiaba, con documentación técnico-científica e histórica en mano ${ }^{5}$, Ramón Antonio Rodríguez, al calde de Armero (quién se convirtió tristemente en el último de su historia) se desplazó de su municipio en busca del apoyo nacional y departamental que le garantizaran evitar una tragedia de magnitud gigantesca. Fue despachado hacia su terruño asegurándosele que el Gobierno Nacional "tomaría las medidas del caso" (Cruz, C. et ál. 1995). Sin duda alguna para el gobierno central "la problemática de Armero" no era de la "dimensión necesaria" para demandar su atención, desviarlo de asuntos fundamentales de Estado y más allá aún, destinar con celeridad importantes recursos institucionales, humanos y financieros.

En la respuesta ante el desastre el mecanismo fue el mismo: decisiones centrales que desconocían las reales dimensiones de la tragedia y que retardaban y entorpecían la capacidad operativa de respuesta.

$\mathrm{Y}$, a las seis de la tarde del trece de noviembre, cuando el Dr. Roberto Ramírez, Presidente de la Cruz Roja de Armero, llamó a Manizales, le dijeron que todo estaba normal. Pero la verdad es que la avalancha venía bajando desde las cuatro de la tarde. Lo que ocurrió fue que se represó varias veces. Y las telefonistas de San Pedro, llamaron a don Campo León

${ }^{5}$ Consistente en el informe ya referido del INGEOMINAS y en las crónicas de la colonia en la que hacían referencias a erupciones y avalanchas catastróficas sufridas en la zona donde estaba localizada la ciudad. 
Castro para que le dijera a la gente que saliera, pero desafortunadamente él no estaba autorizado; llamó al Alcalde y este al Gobernador y todo terminó en que no pasaba absolutamente nada, que todo estaba normal (Cruz, C. et ál. 1995:115).

Ello sin duda disparó el impacto del evento, tanto en el lugar mismo (muertes) como en el escenario postdesastre (dispersión familiar, desatención social, recuperación, readaptación social y laboral, etc.). .."fue mucha la gente que murió por falta de ayuda... Algo que me pareció mal por parte de quienes manejaban los helicópteros, fue que se de dicaron a sacar una cantidad de personas muertas que estaban en el lodo. El primer día se dedicaban a eso, en lugar de haberse dedicado a sacar la gente que estaba herida y prestarles una ayuda técnica..." (Cruz, C. et ál. 1995:113).

En esa misma dirección, a través de los medios de comunicación, el gobierno trató de desviar la atención del país y centrar su mirada en el caso trágicamente difundido de Omayra Sánchez, la niña cuyo dolor y muerte fue registrada, en directo y paso a paso por radio y televisión. Con ello se minimizó el verdadero impacto de la tragedia y se tejieron redes de solidaridad en vez de realizar juicios de responsabilidades.

En la lógica de organización del Estado ya descrita y apoyado en condicionantes históricos (concentración de tierra y factores productivos, rígida estructura de clases sociales, presencia de gamonales) se propició un acceso inequitativo al poder político y económico. Esto, que se expresa no sólo nacional sino regionalmente, puso en debilidad y desventaja comparativa a la ciudad, el municipio y el departamento en su totalidad, en su capacidad de incidencia en el poder (en esa estructura jerárquica) y en la toma de decisiones (favorabilidad o no). Igualmente, el hecho de que la ciudad tuviera como actividad principal la agrícola, posiblemente, hizo que se vieran sus factores de producción, móviles, de fácil recuperación (el suelo no resultaría destruido y las actividades agrícolas muy "rápidamente" podrían retomarse, en contraste con una infraestructura productiva industrial que sí sufriría impactos irrecuperables) o de importancia relativa. Por la dimensión del evento ocurrido, rugosidades sociales (heterogeneidades) no fueron importantes 
y el impacto se dio casi prácticamente igual para todas las clases sociales de la ciudad. Empero, diferencias topográficas que reflejaban en alguna medida acceso diferencial al suelo y su renta (ocupación distante del centro y en áreas altas y por tanto de menor valor), jugó papel favorable para los estratos sociales más bajos.

Otro factor que jugó a lo largo del tiempo en contra de la población e incrementó su vulnerabilidad fue el desprestigio y descreimiento en la clase política dirigente, tanto a nivel local como regional; ello hizo que tanto en la cadena de poder, como en el escenario local, no fuera escuchado el alcalde en sus intentos de alertar, movilizar y salvar la ciudad. Sus razones y argumentos fueron recibidos o con sospecha o con escepticismo. Igualmente, al parecer las alertas generadas por los organismos estatales, que según los informes institucionales, existieron, no fueron acatadas probablemente por las razones descritas (falta de credibilidad del Estado y de aquello que "en apariencia" lo representara).

Los recortes de prensa (El Tiempo, El Espectador y de la revista Cromos) y los mismos sobrevivientes (entrevistas en campo) reconocen un fuerte arraigo en la población de una visión teológica y de acatamiento del clero; anécdotas diversas le adjudican una fatal responsabilidad al párroco de la ciudad en la dimensión de la tragedia, por cuanto había expresado en esos días "que no temieran, que Dios los protegería". Estas expresiones que si bien sin contexto alguno pueden hacer parte inocentemente y rutinariamente de cualquier homilía, pudo haber demarcado un destino trágico para muchos; la minimización o desconocimiento total de las alertas y sugerencias pudo responder en buena medida a esta razón.

Finalmente y no menos importante, la inexistencia absoluta de una cultura de la prevención hizo que se completara el cuadro de causas de fondo de la vulnerabilidad. Conceptos que hoy en día son familiares ya para un alto porcentaje de la población (como vulnerabilidad, riesgo, desastre, prevención, mitigación, etc.) eran prácticamente desconocidos en ese momento y no existía el convencimiento, consciencia y certeza, ni en las autoridades ni en la población, sobre los bajos costos de prevenir en relación con los altísimos de atender y recuperar. Ilógicas e 
irrisorias parecían entonces las cifras necesarias para tomar medidas que previnieran el desastre. En otros términos, no existían planes ni programas algunos de mitigación o contingencia, incluso los de evacuación no fueron interiorizados por la población y fallaron: "mucha gente se subió en carros y afanados por salir cogieron camino hacia Guayabal, pero como ya eso venía cerca, arrolló todos los carros". (Cruz, C. et ál. 1995:60).

Además, las versiones distintas de prensa confundieron a la población y redujeron la capacidad de respuesta de ella;

esa noche dormíamos tranquilamente, claro que sí habíamos oído las noticias en la radio, pero decían que estuvieran tranquilos, que solamente mojaran un pañuelo con agua para taparse la nariz y que no se sintiera el olor a azufre y todo eso que se estaba sintiendo (Cruz, C. et ál. 1995:59).

Uno de los errores más grandes que se cometieron, fue no haberle dicho a la gente la verdad. A mí siempre me ha parecido que a la gente debió habérsele dicho la verdad, por dura que fuera, por cruel que fuera. A nosotros nos presentaban unas películas donde nos mostraban el nevado del Ruiz y nos decían cómo podía ser un deshielo, pero jamás nos dijeron la capacidad destructiva que podía tener. Nos decían que si ocurría un deshielo eso se podía venir por el Lagunilla y dado el caso de que fuera fuerte alcanzaría a coger algunas calles. O sea, lo que yo pude captar, nos decían que era un espectáculo digno de ver. (Cruz, C. et ál. 1995:114).

Es decir, en este tipo de situaciones más importante que tener múltiples informaciones (versiones) es tener información veraz. En este aspecto los medios masivos de comunicación, a pesar de haber mejorado, tienen aún mucho que aprender.

\subsection{Presiones dinámicas}

Para Wisner, Ben et ál. (2004) las presiones dinámicas canalizan las causas de fondo hacia formas particulares de inseguridad. Se pueden interpretar como elementos de coyuntura que agravan las condiciones estructurales de la vulnerabilidad.

La toma del Palacio de Justicia en Bogotá; el costo económico de reconocer el peligro y su incidencia en la economía local y familiar; 
el crecimiento poblacional y la percepción misma de la amenaza y su familiarización con ella; se convirtieron en las presiones dinámicas que potenciaron la vulnerabilidad.

La toma del Palacio de Justicia, una semana antes del desastre hizo que el gobierno central estuviera completamente volcado, expectante, frente a las implicaciones militares, éticas, políticas, sociales y jurídicas que esta devastación iba a tener en el país. Era "imposible" pensar en un evento de mayor trascendencia en la nación que éste; por tanto, las demandas de auxilio del señor alcalde fueron prácticamente desechadas.

El costo económico de reconocer el peligro fue otro elemento adicional. Costo qué, como podría pensarse, no sólo asume la administración al ver como sus ingresos disminuyen por desplazamiento de actividades y usos del suelo fuera de su municipio, sino también las familias por el impacto que esto tiene en el valor de sus predios y viviendas. Es decir, el costo económico de declarar una zona expuesta a una amenaza se paga colectiva e individualmente (hoy en día se ve con la declaración de áreas en alto riesgo, en los Planes municipales de Ordenamiento Territorial -POTs-) y tiene un valor social que toda la comunidad asume o no.

Centro de relevo agropecuario principal e importante productor de arroz, algodón, maíz, sorgo y ajonjolí y centro de suministro y mercadeo de insumos agropecuarios, herramientas, equipos y créditos; Armero había alcanzado significativos niveles de especialización y centralidad, que mostraban su pujanza y prosperidad ${ }^{6}$. Este hecho influyó en que la población y las mismas autoridades, en un análisis intuitivo de costo/ beneficio para la economía familiar y local, menospreciaran el peligro al que se enfrentaba.

Patente queda en las remembranzas de Carmenza, una sobreviviente que repasa, por decirlo menos, la forma irresponsable como los líderes políticos regionales actuaron en una reunión celebrada en Armero algunos días antes de la avalancha:

${ }^{6}$ Contaba la ciudad con una granja experimental de la Universidad del Tolima, un moderno y dotado hospital de segundo nivel, un hospital neurosiquiátrico, una desmotadora de algodón, un serpentario, servicios bancarios, empresas de transporte, equipo de bomberos y hasta un club campestre. 
Recuerdo que en septiembre de 1985, en Armero, hubo una reunión, allí estuvieron el alcalde de Armero, el Gobernador y Guillermo Alfonso Jaramillo. Le preguntaron al Gobernador si había peligro y él respondía que no pasaría nada, entonces fue cuando Guillermo Alfonso le quitó el micrófono al Gobernador y le dijo: si usted cree que aquí no va a pasar nada yo lo invito, señor Gobernador, a que se venga a vivir aquí con toda su familia y se estaba formando una disputa fea, entonces el Alcalde dio por terminada la reunión (Cruz, C. et ál. 1995:115).

Igualmente, el crecimiento poblacional presentado en la ciudad como respuesta a su alto dinamismo económico hizo que creciera de forma importante (era el tercer municipio poblacionalmente más denso del departamento y contaba con 15 barrios y 32.000 habitantes aproximadamente, según el censo de ese año) y ello expuso un número significativo de población al peligro.

La percepción misma de la amenaza y su familiarización con ella fue sin discusión alguna otra presión dinámica que incremento las condiciones de vulnerabilidad de la población. Casi un año de actividad volcánica sin impactos distintos a la presencia de cenizas, favorables por demás a las actividades agrícolas, seguramente hizo que la población se sintiera, para ese entonces, relativamente a "salvo" y creyera que eran exagerados, prejuiciosos o malintencionados los llamamientos a evacuar. Esta percepción y valoración del volcán y su probable impacto es resultante de la incredulidad de un impacto de tal magnitud por un fenómeno cuyo origen es tan distante ("que se preocupen los de Manizales", dijo alguna vez un político local, refiere don Ernesto Triana) 7 ; segundo, la aparente inactividad de casi siglo y medio del volcán (por cuanto la de principio de siglo pasó casi inadvertida y no había referentes históricos de ella) y tres, su mismo carácter latente "que parecia que si despertaba, que hacía erupción y nada" (desconociendo con esto la verdadera naturaleza de los eventos volcánicos). Consecuentemente con ello, la población y los cuerpos de socorro terminaron, durante esos 11 meses de actividad, habituándose al volcán y su rutina diaria.

\footnotetext{
${ }^{7}$ Entrevista hecha en la zona con sobrevivientes de la tragedia.
} 
Estas palabras de una sobreviviente ilustran el hecho fatal:

Un día que en Armero cayó ceniza, los agentes del Cuerpo de Bomberos pasaron por los barrios diciendo: aprendamos a convivir con el fenómeno del Volcán nevado del Ruiz y del Volcán Arenas, éstos son cambios de la naturaleza con los cuales debemos convivir. Nos decían: cierren las ventanas y prendan los ventiladores. ¿Cómo es posible que unas personas que no tienen el más mínimo conocimiento sobre estos fenómenos, estén autorizadas para decirle eso a toda una ciudad? lo mismo decían las emisoras, de ahí que todo Armero se tranquilizó (Cruz, C. et ál. 1995:115).

\subsection{Condiciones inseguras}

Las condiciones inseguras las entienden Wisner, et ál. (2004) como las formas particulares en que la vulnerabilidad de una población se expresa en tiempo y espacio en relación con una amenaza.

Para el caso de Armero, es admisible mencionar como condiciones inseguras la localización inadecuada de la ciudad, la falta de una preparación para el evento (plan de contingencia) y el relativo retardo en la expresión en el valle de la amenaza originada en el nevado (sistema de amenazas).

La localización de Armero en la salida de la garganta del cañón del río Lagunillas, se explica por las condiciones de fertilidad de los suelos que le genera una alta vocación y potencial agrícola. El alto costo de localizarse allí (en relación con lo aparentemente eventual de un acontecimiento de este tipo) se asume precisamente por las ventajas comparativas de su localización y la explotación real (y cotidiana) de sus suelos. Es decir, las razones que hacen que su localización sea inadecuada son paradójicamente las mismas que la favorecen.

Suplementariamente, cuando se emplazó la ciudad en ese lugar no había plena consciencia sobre los niveles de exposición que asumían. Una vez localizada la ciudad la evaluación es entre la probabilidad de ocurrencia de un evento incierto de efectos inciertos vs. la certeza de explotación agrícola de sus suelos.

La falta de una preparación para el evento creo que ha sido evidente a lo largo de la exposición de los hechos, tanto los referidos directamente 
por los sobrevivientes como los tomados de fuentes secundarias. A pesar de lo "creíble" que resultaba el escenario visualizado, parece ser que muy pocos en verdad "creyeron" que algo así podría pasar y actuaron en consecuencia.

Otra cosa es que yo fui a esas películas, porque donde yo trabajaba las presentaron y era obligación verlas, de lo contrario yo no las hubiera visto, porque a pesar de que la daban por sectores la gente casi no asistía. En realidad nunca nos dijeron: ustedes se van a morir si se quedan en Armero. Si nos hubieran dicho eso, seguro que no hubiera habido tantos muertos porque a uno le dejan la inquietud y ya verá qué hace; es cierto que uno queda alarmado, pero es mejor estar así y no estar tan tranquilo. Porque si uno ve que un problema no es tan grave no le presta atención, pero cuando se da cuenta ya se le salió de las manos, es mejor estar con malicia (Cruz, C. et ál. 1995:114).

A pesar de la presencia de varias instituciones y cuerpos de socorro, incluso los mismos días de la tragedia (miércoles, jueves y viernes) el impacto fue devastador; sin duda alguna los altos niveles de desarticulación en los que operaban (frente al manejo de la información, la línea de mando definida y los mismos planes previstos por $\mathrm{c} / \mathrm{u}$ de ellas) tuvo mucho que ver allí.

Otra cosa es que hay gente que dice que a nosotros, los de Armero, nos habían avisado, eso es mentira, porque yo acostumbraba ir todos los miércoles donde mamá, ella vivía en la vereda San Jorge. Ese miércoles trece de noviembre, cuando yo pasé para donde ella, estaba el carro de la Universidad de Caldas y al pasar por la Cruz Roja le pregunté a los muchachos que estaban ahí, qué pasaba, y ellos me dijeron que nada, entonces me volteé por la calle once y luego pasé por la doce; ahí estaban los de la defensa civil afuera, también les pregunté y me dijeron lo mismo. El padre estaba en la misa y estaba diciendo: si de pronto pasa alguna cosa, lleven enlatados, no oí más, pero no era porque él supiera, porque él tampoco sabía, nadie sabía la magnitud de eso. El que diga: yo sabía la magnitud de eso, es un mentiroso. Sinceramente Dios es el único que sabía de la magnitud (Cruz, C. et ál. 1995:91). 
Finalmente, el relativo retardo en la expresión en el valle de la amenaza originada en el nevado, hizo que a pesar de tener la certeza de la explosión del volcán y de la lluvia de piroclastos y emisión de cenizas; en el imaginario colectivo, seis horas después, se pensara que si no había pasado nada, ya no pasaba. Y la población se acostó a dormir como cualquier otra noche, como tantas otras noches en Armero.

\section{A modo de conclusión}

El cuadro presentado hace sin duda del desastre de Armero un evento de una enorme complejidad no sólo natural sino social. El encadenamiento de elementos de carácter volcánico, climático, hidrológico y geomorfológico muestran lo brutal que pueden resultar estas dinámicas en las gargantas de los abanicos aluviotorrenciales. En el mismo sentido, la combinación de vulnerabilidades física, social, política, institucional y cultural, agravó y complejizó aún más la situación. Preponderante papel jugó allí la institucional en donde por elementos estructurales como de coyuntura hizo que los tomadores de decisiones menospreciaran al evento en sí y a la ciudad misma.

En adelante, se abre una historia de tragedias para los sobrevivientes que los hace pensar que no resultaron tan favorecidos por haber salido con vida. Además de cargar con las imágenes de devastación y muerte y del duelo propio y de sus vecinos, familiares y amigos; el atropello, la exclusión y la marginalidad se convierten en la constante para los Armeritas.

Varias enseñanzas deja esta tragedia, el Sistema Nacional de prevención y atención de desastres; la absoluta certeza de la necesidad de consolidar una cultura de la prevención, que inicia con el sistema, pero no se agota allí; el ser más sensible y respetuoso con la naturaleza y sus señales de vida y muerte; pero por sobre todo, la obligatoriedad de todos los comprometidos con el tema, independientemente de su ángulo de acercamiento, de construir el concepto de riesgo aceptable, su operacionalización y las estrategias que nos garanticen que estemos en él o por debajo de él y nunca por encima. 
Si bien es cierto que prácticamente ningún país del mundo estaría preparado para atender un desastre de las proporciones de lo ocurrido en Armero, es cierto también que la dimensión de lo que ocurrió se alcanzó precisamente por la carencia de una política eficaz de planificación del riesgo, como un elemento no coyuntural sino estructural al territorio, su ocupación y evolución. En otros términos, mientras existan eventos potencialmente amenazantes (independientemente de su génesis y mecanismos funcionales) que se expresen sobre la superficie del planeta y a la vez una población expuesta a esta amenaza, la planificación para el riesgo será una variable estructural para evitar desastres. Difícil encontrar, a lo largo y ancho del globo, una situación que se escape, en mayor o menor medida, a la interacción entre condiciones naturales-amenaza vs. ocupación-vulnerabilidad y su consecuente exposición al riesgo.

Es decir, el tema de los riesgos es de orden capital en el ordenamiento del territorio para un país como Colombia, por cuanto no sólo define la posibilidad de pérdida en vidas humanas, bienes materiales y tejido social, impactos que de por sí ya justifican su realización; sino qué por sus condiciones geológicas, fisiográficas, geomorfológicas, hidro-climáticas y socio-culturales, las situaciones potencialmente amenazantes son permanentes y los niveles de exposición, desafortunadamente en vez de ir disminuyendo, están aumentando considerablemente. Es por esta razón que resulta central, en el contexto del ordenamiento espacial del territorio, definir políticas de uso y ocupación del suelo que reduzcan la posibilidad de configuración de situaciones de riesgo; es decir, que además que respondan a las necesidades inmediatas, rebasen la coyuntura (acciones a corto, mediano y largo plazo); pero sobre todo, sean integrales y armónicas al territorio (que reconozcan e incorporen las posibilidades y restricciones de orden institucional, político y socio-cultural y a su vez articulen los objetivos, metas y estrategias de los planes sectoriales con el de Ordenamiento). 


\section{Figuras}

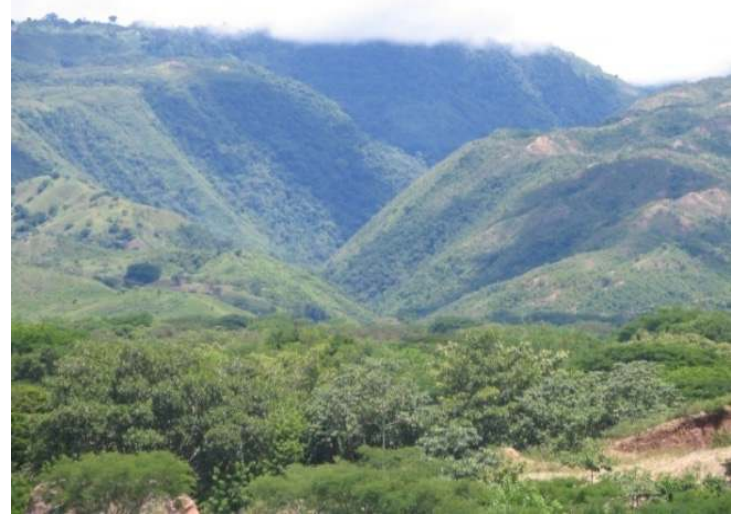

Figura No. 1 Cañón del río Lagunillas, próximo al piedemonte. Nótese la morfología que facilita la formación de presas. Foto tomada por el autor.

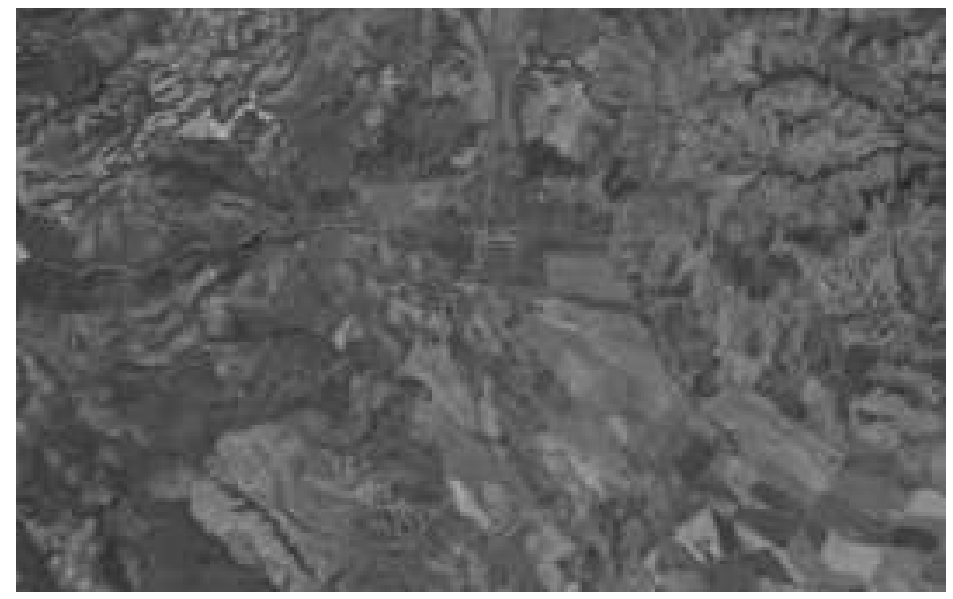

Figura 2. Cono aluviotorrencial del río Lagunillas, donde se asentaba la ciudad de Armero. Nótese, al centro de la imagen que aún se conserva la morfología de calles. Fuente: tomada de Google Maps 


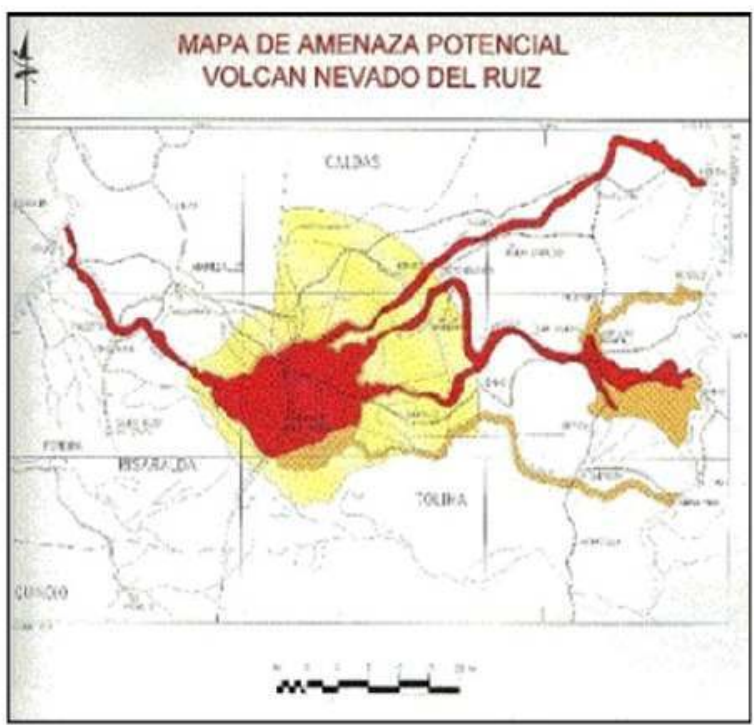

Figura No. 3. Mapa de amenaza del volcán nevado del Ruiz. 1986.

Tomado de: Atlas de Amenaza Volcánica en Colombia. INGEOMINAS, 2000.

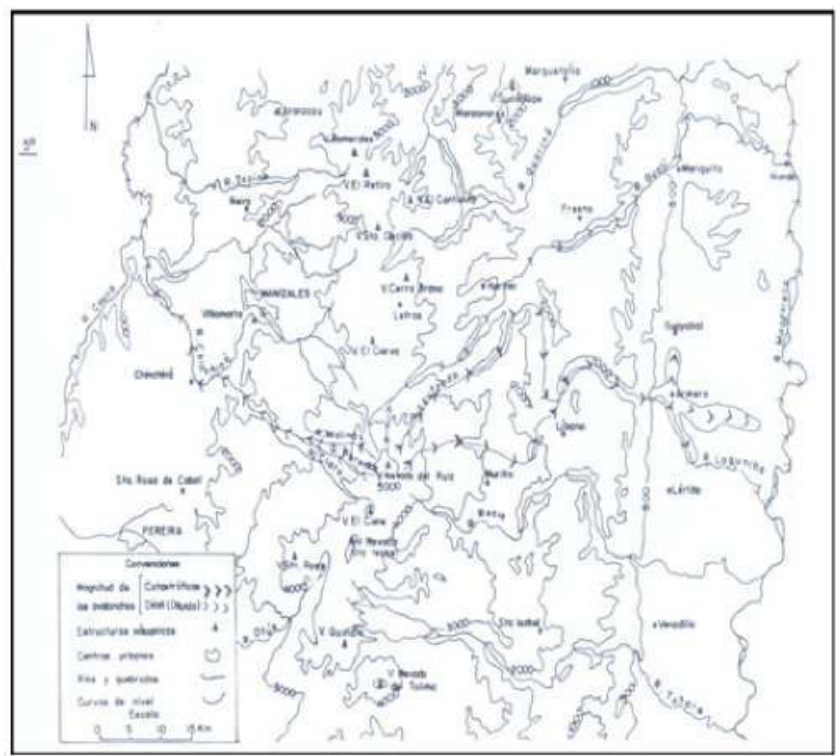

Figura No. 4. Recorrido de las avalanchas de lodo (lahares) durante la erupción de 13 de noviembre de 1985. Tomado de: Flórez, A\& La-Rotta, E. (1986d). 

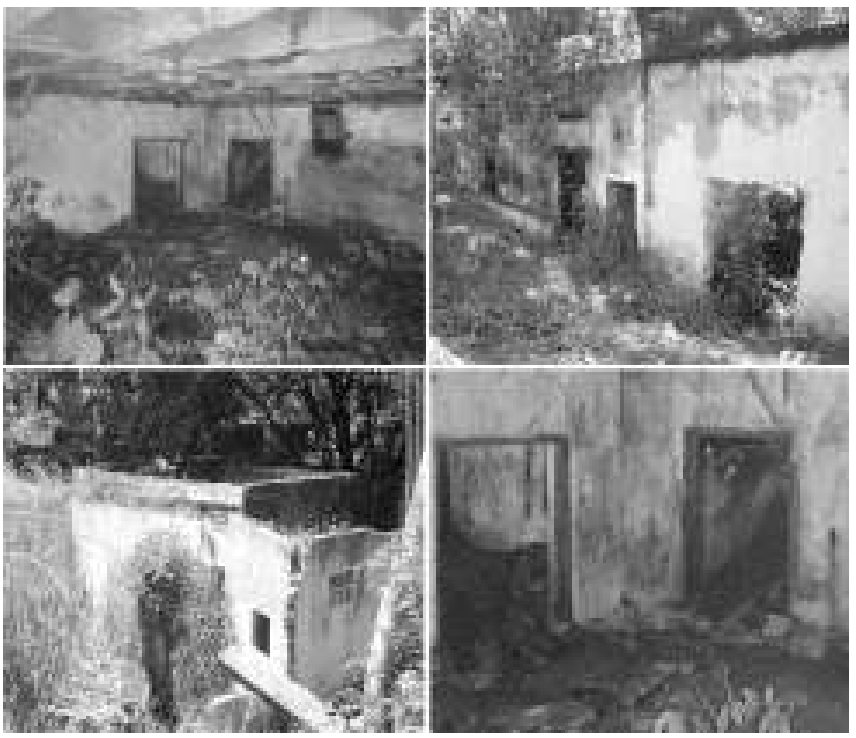

Figura 5. Armero. Mosaico de los vestigios de la avalancha del 13 de Noviembre de 1985. Nótese la altura alcanzada por el lodo ya seco y la devastación en las viviendas que quedaron en pic. Fotos tomadas por el autor.

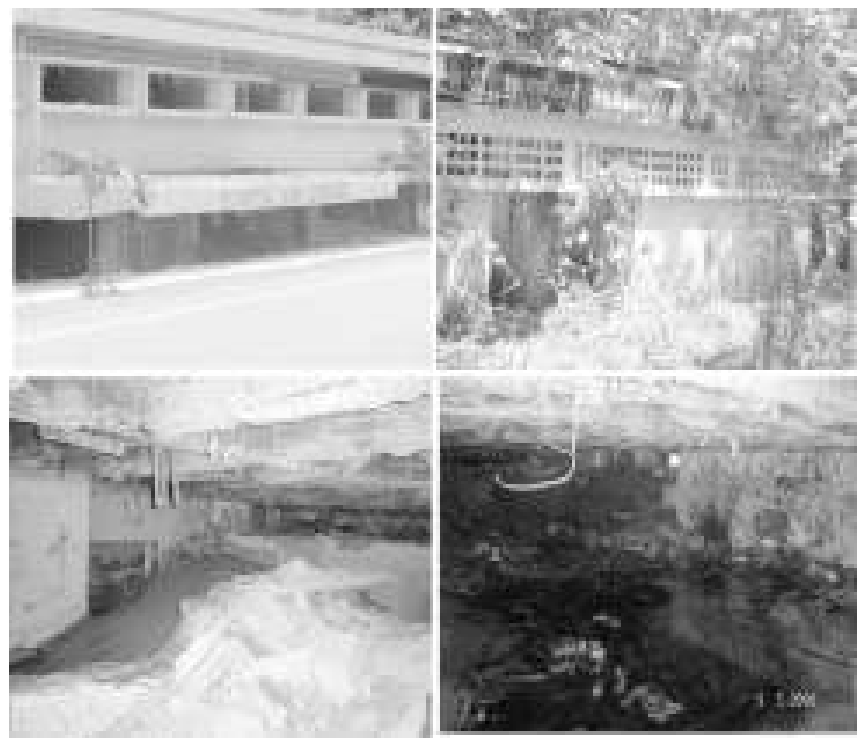

Figura 6. Hospital San Lorenzo de Armero. Fachada principal, costado e interior del primer piso. Nótese la altura alcanzada por la avalancha. Fotos tomadas por el autor. 

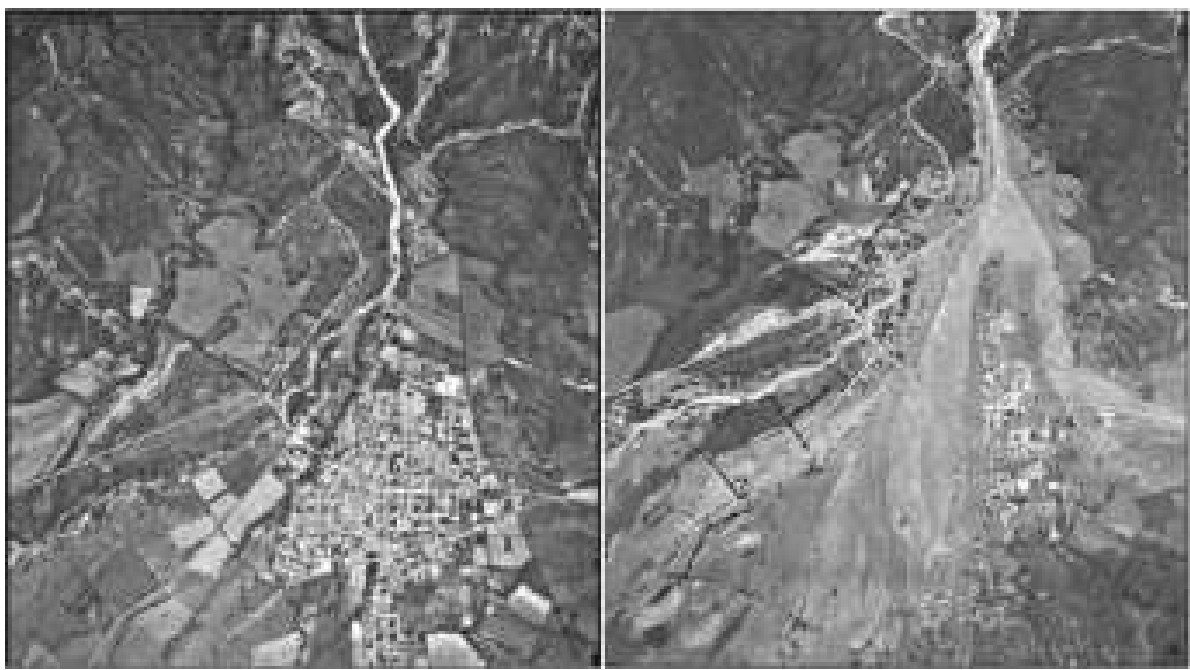

Figura No. 7. Mosaico Aerofotográfico que muestra a Armero antes y después de la tragedia. Nótese la localización de Armero en el ápice del cono y la dimensión alcanzada por la avalancha. Fotos tomadas por el autor de valla informativa localizada en el lugar de los hechos. 


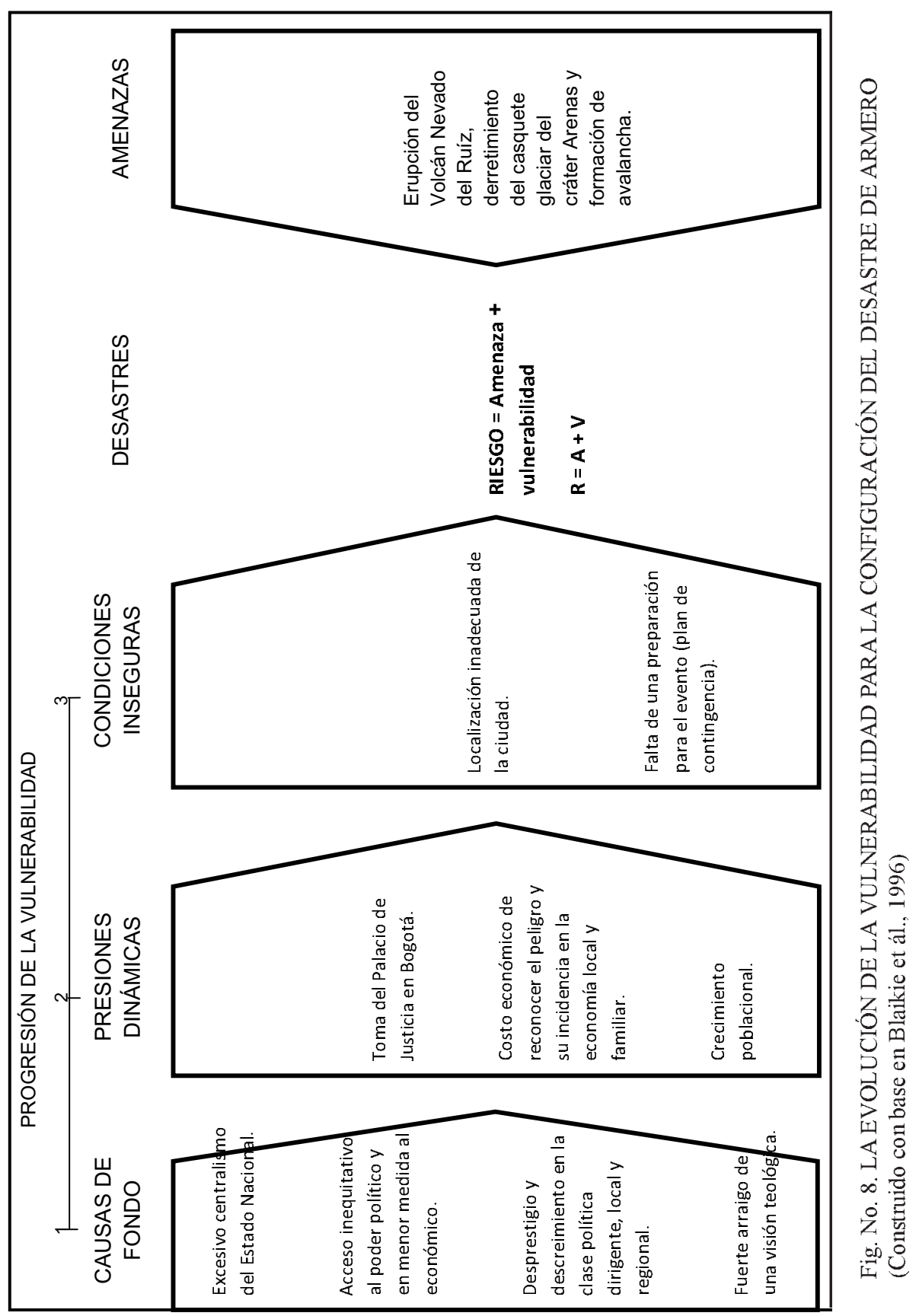




\section{Tablas}

Tabla No. 1. Masas glaciares en los nevados del país.

\begin{tabular}{|c|c|c|c|}
\hline Nevado & Altitud m.s.n.m. & Superficie $\mathbf{k m}^{2}$ & Volumen $\mathrm{m}^{3} \times \mathbf{1 0}^{6}$ \\
\hline Ruiz (antes del 13-11-85) & 5.300 & 19.00 & 342 \\
\hline Ruiz (después del 13-11-85) & 5.300 & 17.05 & 294 \\
\hline Santa Isabel & 4.965 & 8.62 & 112 \\
\hline Tolima & 5.215 & 2.98 & 25 \\
\hline Huila & 7.750 & 15.58 & 259 \\
\hline
\end{tabular}

Fuente: Tomado de Flórez, A \& La-Rotta E. (1986d: 163)

Tabla No. 2. Actividad histórica del volcán nevado del Ruiz.

\begin{tabular}{|c|c|c|}
\hline FECHA & VEI & EVENTOS ERUPTIVOS E INTERVALOS DE INACTIVIDAD \\
\hline 1989-09-01 & 1 & Caída de cenizas, lahar en río Lagunillas \\
\hline $1985-11-13$ & 3 & Erupción sub-pliniana \\
\hline $1985-09-11$ & 1 & Caída de cenizas, lahar en río Lagunillas \\
\hline \multicolumn{3}{|c|}{ Intervalo de inactividad de 69 años } \\
\hline 1916 & $1 ?$ & Caída de cenizas \\
\hline \multicolumn{3}{|c|}{ Intervalo de inactividad de 71 años } \\
\hline $1845-02-19$ & 3 & Avalancha de escombros, lahares \\
\hline 1833 & & Actividad fumarólica \\
\hline 1831 & 1 & Actividad fumarólica y caída de cenizas \\
\hline $1829-06-18$ & 1 & Caída de cenizas \\
\hline $1828-06$ & 1 & Explosión freática \\
\hline \multicolumn{3}{|c|}{ Intervalo de inactividad de 23 años } \\
\hline $1805-03-14$ & 1 & Caída de cenizas \\
\hline \multicolumn{3}{|c|}{ Intervalo de inactividad de 182 años } \\
\hline 1623 & 1 & Actividad fumarólica. Cráter Arenas \\
\hline \multicolumn{3}{|c|}{ Intervalo de inactividad de 28 años } \\
\hline $1595-03-12$ & 3 & Avalanchas de escombros, lahares \\
\hline \multicolumn{3}{|c|}{ Intervalo de inactividad de 25 años } \\
\hline 1570 & $1 ?$ & Incandescencia volcánica \\
\hline \multicolumn{3}{|c|}{ Intervalo de inactividad de 29 años } \\
\hline 1541 & 1 & Actividad fumarólica \\
\hline \multicolumn{3}{|c|}{ No se puede conocer actividad histórica antes de 1541} \\
\hline Probable inter & e inact & idad de 190 años \\
\hline
\end{tabular}

Fuente: Tomado de Borrero, C. \& Cruz, G. (1:3). 
Tabla No. 3. Pérdidas económicas dejadas por el desastre de Armero.

\begin{tabular}{|l|l|c|}
\hline \multicolumn{1}{|c|}{ SECTOR } & \multicolumn{1}{c|}{ COMPONENTES } & \multicolumn{1}{c|}{$\begin{array}{c}\text { PÉRDIDAS } \\
\text { (MILLONES U.S. \$) }\end{array}$} \\
\hline Social & Educación salud, vivienda, empleo. & 92.8 \\
\hline $\begin{array}{l}\text { Infraestructura fí- } \\
\text { sica }\end{array}$ & $\begin{array}{l}\text { Acueducto y alcantarillado, vías, electrici- } \\
\text { dad, telecomunicaciones. }\end{array}$ & 68.5 \\
\hline productivo & $\begin{array}{l}\text { Industria y comercio, agricultura, ganadería, } \\
\text { hidrocarburos }\end{array}$ & 50.6 \\
\hline
\end{tabular}

Fuente: Construido a partir de datos de González. 


\section{Bibliografía}

Acosta, Carlos. (1982), "Colombia y la tectónica de placas", en: Revista Geografía, No. 3, junio 1982, Universidad Nacional de Colombia.

Barrero, L. et ál. (1969), "Actividad ígnea y tectónica en la cordillera central durante el Mesocenozoico", Boletín Geológico, Vol. 17, Nos. 1-3, p. 145-173, Ingeominas, Bogotá.

Borrero, Carlos \& Cruz, Gabriel. (), "Aproximación a la predicción del riesgo por la actividad del volcán nevado del Ruiz". Documento de Internet.

Cardona, Omar. (1990), "Términos de uso común en manejo de riesgos", Bogotá, ed. DPAD.

Coch, Robert. (1995). "Geo-hazards", New Jersey, Macmillam.

Cruz, Carmen, et ál., (1995), "Armero: diez años de ausencia", Fondo Resurgir-FES, Ibagué.

Fischer, R \& Schmincke, H. (1984), "Pyroclastic rocks", Ed. Springer, New York.

Flórez, Antonio. (1983), "Cadena volcánica de los Coconucos, cordillera central", en: Revista Colombiana Geográfica (10) No. 2, p. 33-56.

(1986a). "El volcán nevado del Ruiz, Cumanday o Tama", en: Revista Nueva Colombia. No. 1, p. 54-75, IGAC, Bogotá.

Flórez, Antonio. \& F. Ochoa, (1986c). "La erupción del Volcán del Ruiz", en: Revista Nueva Colombia, No. 2, p. 16-33. IGAC, Bogotá.

Flórez, Antonio \& La-Rotta, Esperanza. (1986d). "Riesgos inherentes a los fenómenos volcanoglaciares en la cordillera Central Colombiana", en: Revista Cartográfica. No. 49/50, p. 159170, Instituto Panamericano de Geografía e Historia, México.

González, Jorge. (Sin fecha), "La erupción del volcán nevado del Ruiz", en: I Taller Latinoamericano de reducción de los desastres naturales en la infraestructura energética.

Hermelin, Michel. (1993), "Medio ambiente y plan de desarrollo municipal", Bogotá, ed. Fondo nacional de calamidades, PNUD y DHA-UNDRO.

Kovach, Robert. (1995), "Earth's fury. An introduction to natural hazards and disasters", New Jersey, Prentice-Hall.

Lonsdale, Peter. (1978), "Ecuatorian subduction system", en: Bulletin The American Association of Petroleum Geologist, Vol. 62, No. 12.

Luschen, E. (1983), "Recent tectonics of the northern Andes according to geophysical and geodetical measurements in Colombia". ZBL. Geol. Palaont. reil I Nos. 3-4, p. 304-317, Sttutgart.

Medina, J. (1992), "Fenómenos geodinámicos, estudio y medidas de tratamiento", Lima, Perú, ed. Tecnología intermedia ITDG.

O.E.A., (1993), "Manual sobre el manejo de peligros naturales en la planificación para el desarrollo regional integrado", Washingthon, D.C., EE.UU.

Oliver, Jack, (1972), "Contributions of seismology to the plate tectonics", en: Bulletin The American Association of Petroleum Geologist, Vol. 56, No. 2.

ONAE, (1987), "Atención de emergencias", Presidencia de la República, Bogotá.

Paris, G. \& P.A. Marín. (1979), "Generalidades acerca de la geología del departamento del Cauca", p. 38, Ingeominas, Bogotá.

PNUD (UNDRO - DAH), (1991), "Vulnerabilidad y evaluación de riesgos", la . edición.

Ramírez, Jesús. (1968), "Los volcanes de Colombia", en: Revista Colombiana de Ciencias, Vol. 13, No. 50, p. $227-235$.

(1975), "Historia de los terremotos en Colombia", Bogotá, IGAC. 
Robertson, Kim et ál. (2002), "Geomorfología volcánica, actividad reciente y clasificación en Colombia”, en: Revista Cuadernos de Geografía, Vol. XI No. 1-2, Universidad Nacional, Bogotá.

Romero, \& Maskrey, E. (1993) "Cómo entender los desastres naturales", en: Los desastres no son naturales, LA RED, Colombia, Tercer mundo editores.

Scheidegger, A., (1987), "Los principios fundamentales en la evolución del paisaje", CATENA Suppl 10:199-210. Viena, Traducción Antonio Flórez. (1988), "La dinámica de los sistemas morfogénicos", Z Geomorph N.F. Suppl Bd 67:5-15, Berlín, Traducción Antonio Flórez.

Strahler, Arthur. (1992), "Geología física", Barcelona, Omega editores.

Thomas, Javier., (2000), "Las amenazas naturales y el ordenamiento del territorio. Unas notas", Memorias XVI Congreso Colombiano de Geografía, Cali, Universidad del Valle.

(2005), “Amenazas, riesgos y planificación territorial. Un acercamiento metodológico", en: Revista Perspectiva Geográfica, No. 11, Escuela de Posgrado de Geografía, UPTC, Tunja.

Thouret, J.C. A, Murcia, R. Salinas \& N. Batin, (1985), "Cronoestratigrafía mediante dataciones $\mathrm{K} / \mathrm{A}$ y $\mathrm{C} 14$ de los volcanes compuestos del complejo Ruiz-Tolima y aspectos volcanoestructurales del nevado del Ruiz. Memorias del VI Congreso Latinoamericano de Geología (1), p. 385-454.

Toussaint, Jean. (1978), "Grandes rasgos geológicos de la parte septentrional del occidente colombiano". Boletín Ciencias de la Tierra, No. 3, UNAL, Medellín.

Wilches, Gustavo. (1993), "La vulnerabilidad global", en: Los desastres no son naturales, La RED, Colombia, Tercer mundo editores.

Wisner, Ben et ál. (2004), "At Risk". Second edition, London, Routledge Eds.

Recibido: enero 2008

Aceptado: agosto 20 de 2008 